\title{
Central domain deletions affect the SAXS solution structure and function of Yeast Hsp40 proteins Sis1 and Ydj1
}

Julio C Silva ${ }^{1,2,6 \dagger}$, Julio C Borges ${ }^{3+}$, Douglas M Cyr ${ }^{4}$, Carlos HI Ramos ${ }^{5}$ and Iris L Torriani ${ }^{1,2^{*}}$

\begin{abstract}
Background: Ydj1 and Sis1 are structurally and functionally distinct Hsp40 proteins of the yeast cytosol. Sis 1 is an essential gene whereas the $y d j 1$ gene is essential for growth at elevated temperatures and cannot complement sis 1 gene deletion. Truncated polypeptides capable of complementing the sis 1 gene deletion comprise the J-domain of either Sis1 or Ydj1 connected to the $\mathrm{G} / \mathrm{F}$ region of Sis1 (but not $\mathrm{Ydj} 1$ ). Sis1 mutants in which the $\mathrm{G} / \mathrm{F}$ was deleted but G/M maintained were capable of complementing the sis1 gene deletion.

Results: To investigate the relevance of central domains on the structure and function of Ydj1 and Sis1 we prepared Sis 1 constructs deleting specific domains. The mutants had decreased affinity for heated luciferase but were equally capable of stimulating ATPase activity of Hsp70. Detailed low resolution structures were obtained and the overall flexibility of Hsp40 and its mutants were assessed using SAXS methods. Deletion of either the G/M or the G/M plus CTDI domains had little impact on the quaternary structure of Sis1 analyzed by the SAXS technique. However, deletion of the ZFLR-CTDI changed the relative position of the J-domains in Ydj1 in such a way that they ended up resembling that of Sis1. The results revealed that the $\mathrm{G} / \mathrm{F}$ and $\mathrm{G} / \mathrm{M}$ regions are not the only flexible domains. All model structures exhibit a common clamp-like conformation.
\end{abstract}

Conclusions: Our results suggest that the central domains, previously appointed as important features for substrate binding, are also relevant keeping the J-domains in their specific relative positions. The clamp-like architecture observed seems also to be favorable to the interactions of Hsp40 with Hsp70.

\section{Background}

Molecular chaperones are proteins that are involved in assisting the folding and assembly of newly synthesized proteins recognizing non-native substrate proteins predominantly via their exposed hydrophobic residues [1]. However, the conditions for the successful folding in vivo are not always favorable. The cellular environment is crowded and thus protein denaturation and aggregation will be major problems. Thus, there is the need for chaperones that also protect cells from elevated temperature or other cellular stress situations, to achieve successful folding of proteins in vivo. There are several

\footnotetext{
* Correspondence: torriani@ifi.unicamp.br

† Contributed equally

'Department of Condensed Matter Physics, "Gleb Wataghin" Physics Institute, State University of Campinas (UNICAMP), Campinas, SP 13083-859, Brazil
} Full list of author information is available at the end of the article families of Heat Shock Proteins (HSPs), each family acts to assist protein folding in a different way.

An important chaperone family is the $40-\mathrm{kDa}$ Heat shock protein (Hsp40). Chaperones from the Hsp40/ DnaJ family play important roles in cells by working together with molecular chaperone Hsp70 to promote protein folding, assembly, translocation and degradation [2-5]. Hsp40 proteins can interact with the hydrophobic side-chains of non-native polypeptides preventing aggregation [6,7]. Hsp40 can then form transient complexes with Hsp70 presenting non-native polypeptides for subsequent protein folding [8-10]. The members of the Hsp40 family typically contain a J-domain, which regulates the ATP-dependent binding of peptides by Hsp70 $[4,11,12]$.

Members of the Hsp40 family act as molecular chaperones to bind and deliver non-native proteins to Hsp70 and can be divided into three main groups, from 
which two: Type I and Type II are the most studied. The two types are not functionally equivalent [13-15] and exhibit major differences in chaperone activity [16]. In both types the J-domains are connected to the central and C-terminal domains via a G/F-rich (Glycine/phenylalanine-rich) linker (Figure 1).

Type I Hsp40s, such as Escherichia coli DnaJ, yeast Ydj1 and human Hdj2, contain a zinc-finger-like linker region (ZFLR) between the G/F domain and the C-terminus (Figure 1B), and Type II Hsp40 proteins such as yeast Sis1 and human Hdj1 contain a G/M-rich (Glycine/Methionine-rich) domain in the linker region (Figure 1A) [14-17]. Both types have a substrate-binding site located at their $\mathrm{C}$-terminal domain, which is divided in subdomains I (CTDI) and II (CTDII) (Figure 1).

The reason why Type I and Type II Hsp40s exhibit differences in chaperone activity is unknown. Some biochemical and structural studies have already provided some insight into this question, suggesting that the answer resides in their structural differences $[15,18,19]$. Hence, the need for a comprehensive study of their structure is of considerable importance.
High-resolution structural studies with fragments of Sis1 and other Type II Hsp40s indicated that these proteins function as homodimers that have a clamp-like architecture and use a shallow groove located on the surface of monomers to bind non-native proteins $[20,21]$. In addition, the G/F-rich regions of Ydj1 and Sis1 lie adjacent to their putative polypeptide binding domains and they seem to specify the functions of these Hsp40s [22-24]. These structure/function studies together with hydrodynamic analysis showed that both types of Hsp40 proteins form dimers in solution $[6,18,19]$. Dimer formation plays a critical role in Hsp40s chaperone activity because disruption of the dimerization motifs results in severe defects in both chaperone functions $[20,25]$.

Previous results showed that human and yeast Type I and Type II Hsp40s, have distinct quaternary structure $[18,19]$. These results raised the hypothesis that the central domains controlled the quaternary structure of both types of Hsp40s, because in chimeric mutants, in which the central domains of Ydj1 (ZFLR) and Sis1 (G/M) were switched, their properties were exchanged. A

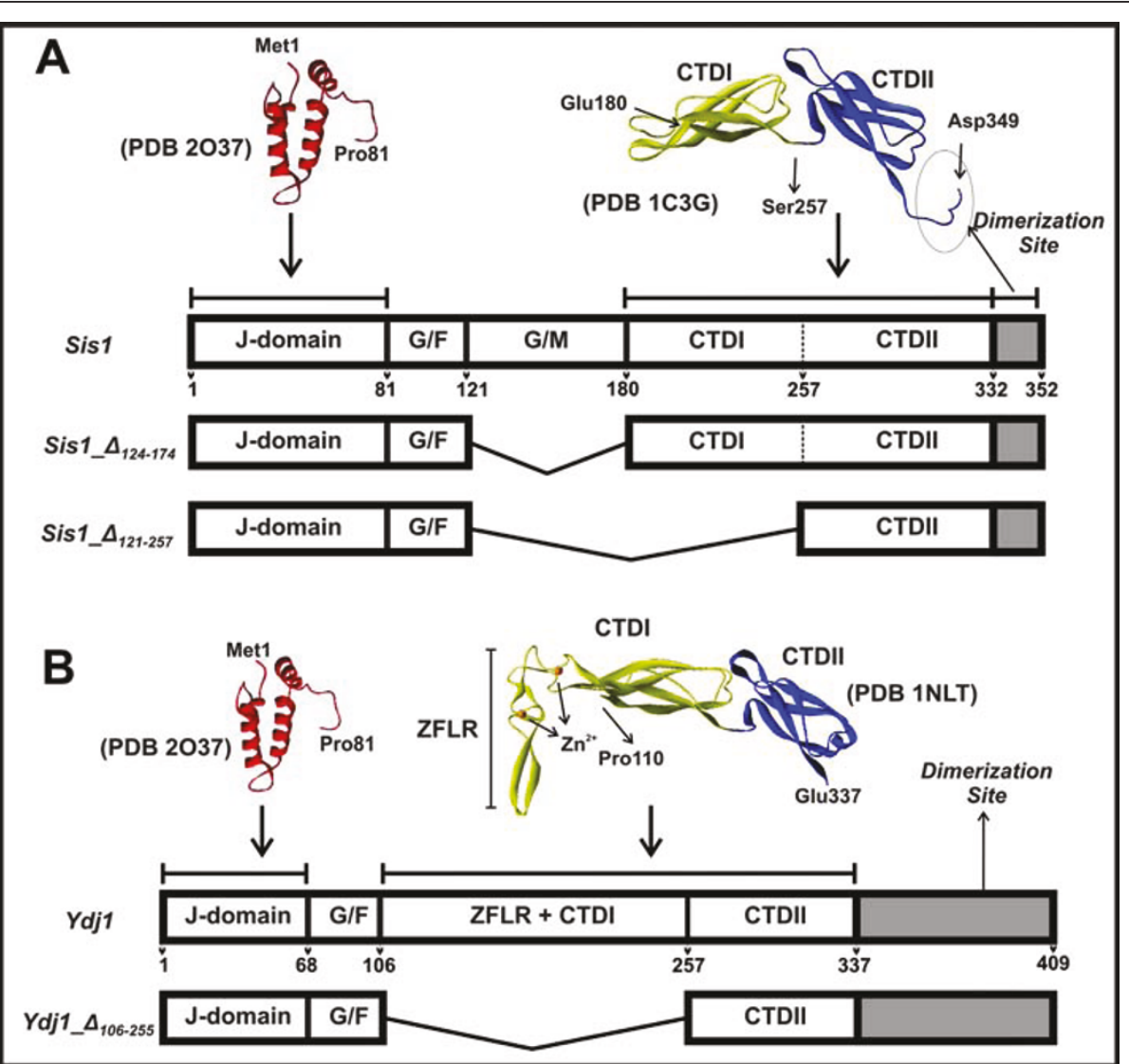

Figure 1 Domain organization of the Hsp40s and mutants. (A) Schematic representation of Sis 1 domains from known high-resolution structures. (B) Schematic representation of Ydj1 domains from high-resolution structures. 
chimeric Ydj1 in which the ZFLR had been switched by the G/M from Sis1 proved to be functionally and structurally similar to Type II Sis1. Correspondingly, a chimeric Sis1 in which the G/M had been switched by the ZFLR from Ydj1 proved to be functionally and structurally similar to Type I Ydj1 $[15,19]$.

To increase our knowledge on the role of the central domains in the structure/function relationship we defined the biophysical and functional features of Sis1 and Ydj1 mutants with deleted central domains that were specific for Type I or Type II Hsp40s. These studies entailed a functional analysis of mutated Hsp40s coupled with biophysical investigation of the quaternary structure by dynamic light scattering, analytical ultracentrifugation and small-angle X-ray scattering (SAXS). A refined solution structure of Sis1 was also obtained using improved SAXS data. The outcome of these studies showed that deletion of either the G/M or the G/M plus CTDI domain regions had minor impact on the overall quaternary structure of Sis1. Consequently, our results suggest that the central domains are important for substrate binding and maintenance of the J-domains in their specific relative positions.

\section{Results and Discussion}

\section{Protein samples}

Sis1 is a yeast member of the Type II Hsp40s family and contains 352 residues arranged in a highly conserved $\alpha$ helical $\mathrm{N}$-terminal J-domain, a disordered middle region (divided into glycine/phenylalanine (G/F) and glycine/ methionine $(\mathrm{G} / \mathrm{M})$ rich regions) and two $\mathrm{C}$-terminal sub-domains (CTDI and CTDII) as shown in Figure 1A. In order to understand the role of the central regions in the structure and function of Type II Hsp40s, two Sis1 deletion mutants were produced: Sis1_ $\Delta_{124-174}$, from which the G/M region had been deleted, and Sis1_ $\Delta_{121}$ 257, from which both the G/M and the CTDI had been deleted (Figure 1A). Ydj1 is a yeast Type I Hsp40 that contains 409 residues also arranged in a highly conserved $\alpha$-helical $\mathrm{N}$-terminal J-domain, a disordered middle region (a glycine/phenylalanine (G/F)), a Zinc finger domain (ZFLR or Cys-rich domain) and a two C-terminal sub-domains (CTDI and CTDII) as shown in Figure 1B. Again, to understand the role of those regions in that protein structure, we also studied a Ydj1 deletion mutant that we named Ydj1_ $\Delta_{106-255}$, which both the Zinc finger-like region (ZFLR) and the CTDI had been deleted (Figure 1B). The mutants were purified with no apparent contamination ( $>95 \%$ pure; Figure $2 \mathrm{~A}$ ) and maintained at $4{ }^{\circ} \mathrm{C}$ to avoid degradation. The folded conformation of the proteins was investigated by circular dichroism (CD) spectroscopy (Figure 2B). As previously shown for the wild-type proteins Sis1 and Ydj1 [19], the mutants had CD spectra of well folded proteins with minima at about 208 and $220 \mathrm{~nm}$ and a positive peak bellow $200 \mathrm{~nm}$ (Figure 2B). The shapes of the spectra indicated that no large unfolded portion was present. This is in good agreement with the results from hydrodynamic measurements (see below).

\section{Hsp40 function}

Hsp40s act by binding an unfolded or partially unfolded protein (client protein) delivering it to Hsp70 and concomitantly stimulating the Hsp70 ATPase activity. ATP hydrolysis by Hsp70 is a crucial step in protein folding assisted by this chaperone. The effect of the deletions on the function of the Hsp40s was assayed by testing both the ability to bind a client protein and the stimulatory effect on the ATPase activity of Hsp70 (Figure 3). First, the ability to bind heated luciferase (a client

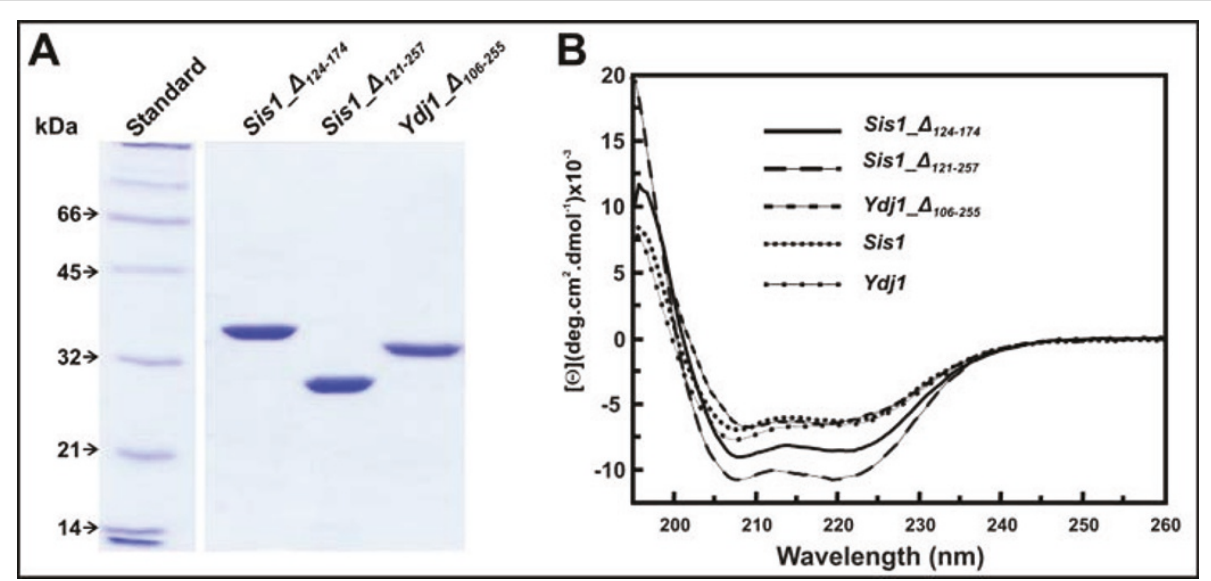

Figure 2 Results from protein expression: (A) SDS-PAGE 12\% showing that the recombinant mutant proteins were >95\% pure. Molecular masses for standard proteins are shown on left. (B) CD spectra of recombinant proteins (10-40 $\mu \mathrm{M}$ ) were measured from 195 to $260 \mathrm{~nm}$ in 25 $\mathrm{mM}$ Tris- $\mathrm{HCl}(\mathrm{pH} 7.5)$ containing $500 \mathrm{mM} \mathrm{NaCl}$ and are shown as molar residual ellipticity $([\Theta])$. 

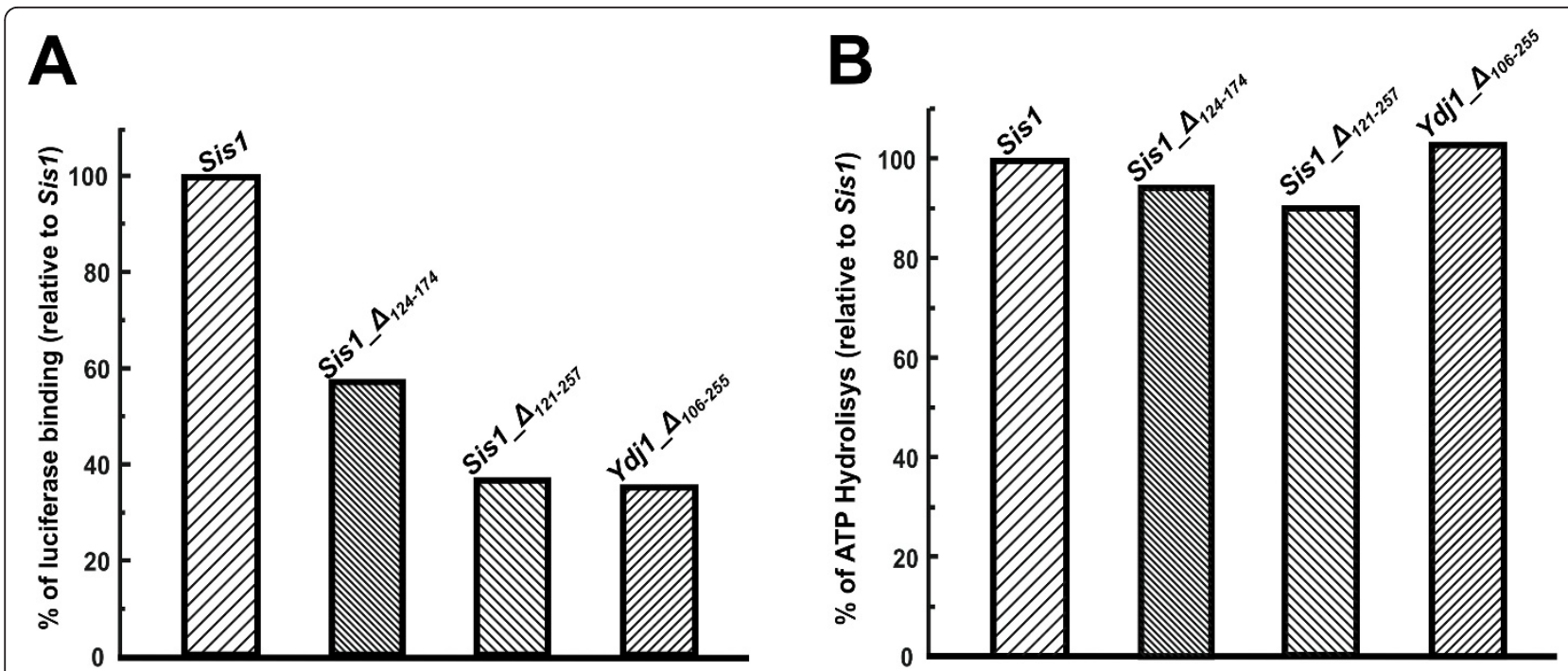

Figure 3 Functional tests: (A) Hsp40s ability to bind client proteins was about 40\%. (B) Hsp40s ability to stimulate the ATPase activity of Hsp70 was about $90 \%$ compared to Sis1. (See text for more details).

protein) was tested and the Sis1 binding was set as standard (100\%). Compared to Sis1, the efficacy of Sis1_ $\Delta_{124-174}$, was of about $60 \%$, and both Sis1_ $\Delta_{121-257}$ and Ydj1_ $\Delta_{106-255}$ were of about $40 \%$ (Figure 3A). Second, the mutants were assayed regarding their ability to stimulate ATP hydrolysis of Ssa1 (Hsp70) and the Sis1 stimulatory effect was set as standard (100\%). Sis1_ $\Delta_{124-}$ 174 and Ydj1_ $\Delta_{106-255}$ had effect similar to that of Sis1, inside the error, and the effect of Sis1_ $\Delta_{121-257}$ was of about $90 \%$ (Figure 3B). For comparison, the performance of Ydj1 in both experiments was similar to that of Sis1, within experimental error (data not shown). The results show that while the deletions decreased in about $50 \%$ the ability to bind client proteins, they seem to have no effect on the ability of the J-domain in interacting with Hsp70. These results suggested that the Jdomains maintained their proper conformation and functionality.

\section{Hydrodynamics}

Sis1 and Ydj1 are dimers in solution and here we used analytical ultracentrifugation (AUC) to investigate the oligomeric status of the deleted mutants. We performed AUC sedimentation velocity (SV) experiments and fitted the data using SedFit that supplied continuous sedimentation distribution $\mathrm{c}(\mathrm{S})$ (Figure 4A). From the maximum of the peaks of the $\mathrm{c}(\mathrm{S})$ curve, the apparent $\mathrm{s}$, which was corrected to standard conditions $\left(\mathrm{s}_{20, \mathrm{w}}\right)$ and plotted against protein concentration (Figure $4 \mathrm{~B}$ ). The extrapolation of $s_{20, w}$ to $0 \mathrm{mg} / \mathrm{mL}$ gave $\mathrm{s}^{0}{ }_{20, w}$ which is an intrinsic property of the protein and contains information about both the molecular mass $(\mathrm{M})$ and the asymmetry of the molecule. Normally, a variation in the value of $\mathrm{s}_{20, \mathrm{w}}^{0}$ induced by external factors ( $\mathrm{pH}$ changes, salt strength, ligands or temperature) is related to conformational changes [26]. The values of $\mathrm{s}^{0}{ }_{20, \mathrm{w}}$ and $\mathrm{D}^{0}{ }_{20, \mathrm{w}}$, obtained from dynamic light scattering (DLS) experiments, are shown on Table 1 . The $M$ values obtained from both the $c(M)$ distribution and the $s / D$ ratio (Equation 4), and the weight average factor $f / f_{0}$ are also shown (Table 1). Our results suggested that Sis1_ $\Delta_{124-}$ 174, Sis1_ $\Delta_{121-257}$ and Ydj1_ $\Delta_{106-255}$ are also dimers in solution and they have an asymmetric or elongated shape as shown previously for Hsp40 proteins [18,19].

\section{SAXS results}

To explore the impact of selective central domains deletion on Hsp40s quaternary structure, SAXS analysis was performed. The corrected and normalized experimental SAXS curves for the proteins Sis1, Sis1_ $\Delta_{124-174}$, Sis1_ $\Delta_{121-257}$, and Ydj1_ $\Delta_{106-255}$ in the q range $0.01<\mathrm{q}$ $<0.25 \AA^{-1}$ are displayed in Figure 5(A), together with the respective regularization fitting (solid lines) resulting from the $\mathrm{p}(\mathrm{r})$ function calculation using GNOM. The corresponding $\mathrm{p}(\mathrm{r})$ functions, shown in Figure 5(B), indicated a slightly elongated shape for all the proteins in solution, confirming the AUC results. The Kratky plots presented in Figure $5(\mathrm{C})$ showed that those proteins are all quite flexible in solution, which gave us a clue about the difficulty in crystallizing them. An inspection of the Porod plots in Figure 5(D) shows that the curves do not contain a significant plateau region indicating well defined particle volumes, but the plots for Sis 1 and Sis1_ $\Delta_{124-174}$ present a fairly flat region in the $\mathrm{q}^{4}$-range $0.0012<\mathrm{q}^{4}<0.0025 \AA^{-4}$, suggesting a more compact conformation for those two proteins. The complete 


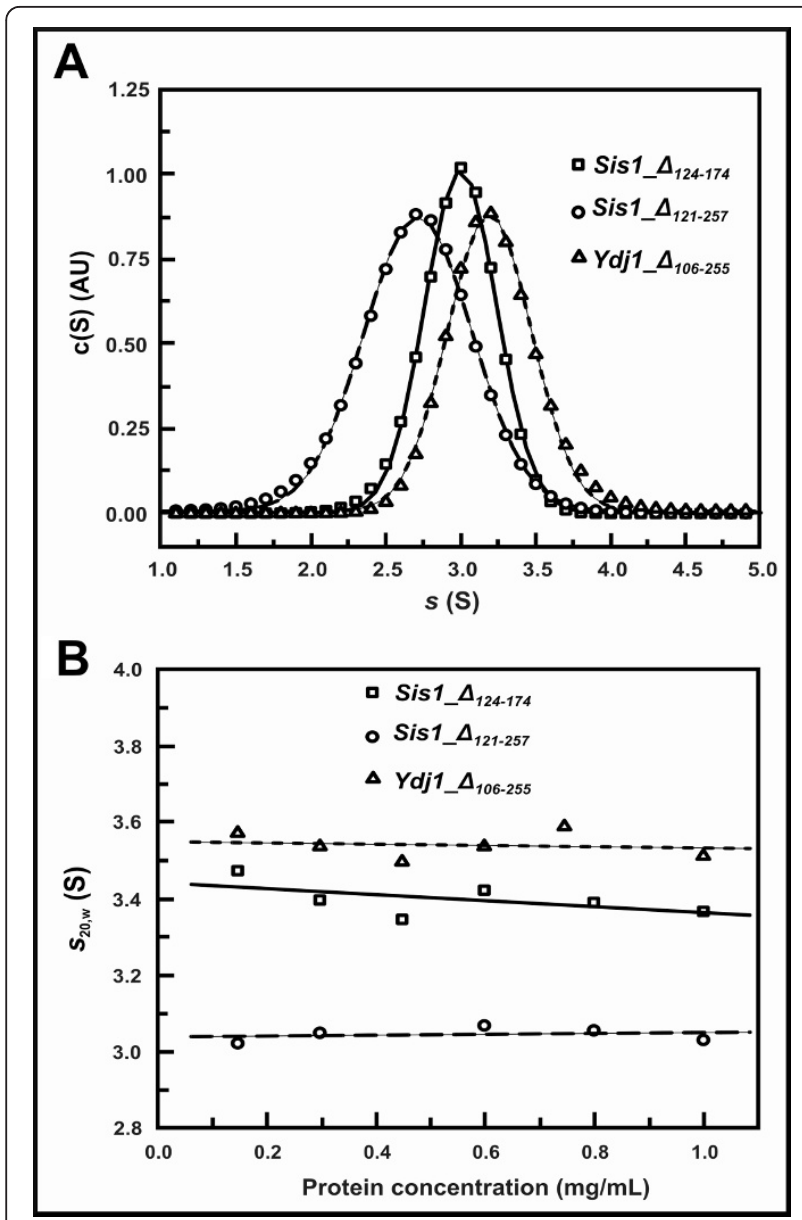

Figure 4 Results from analytical ultracentrifugation (AUC) sedimentation velocity (SV) experiments. (A) The Figure shows experiments using $1,000 \mu \mathrm{g} / \mathrm{mL}$ of protein concentration in 25 $\mathrm{mmol} / \mathrm{L}$ Tris- $\mathrm{HCl}$ (pH 7.5) containing $500 \mathrm{mmol} / \mathrm{L} \mathrm{NaCl}$. (B) The software Sednterp was used to correct the apparent $\mathrm{s}$ to the $\mathrm{s}_{20, \mathrm{w}}$. Proteins $s^{0} 20, w$ values were calculated from the plot of $s_{20, w}$ versus protein concentration and are shown in Table 1. deviation from the Porod regime leads to predict more flexible structures for the Sis1_ $\Delta_{121-257}$, and Ydj1_ $\Delta_{106-}$ 255 proteins. The degree of flexibility of each individual protein is thus confirmed from these plots. The inset in Figure 5(A) displays the $\ln (\mathrm{I}(\mathrm{q}))$ vs. $\mathrm{q}^{2}$ plot within the validity region for the Guinier approximation $\left(\mathrm{qR}_{\mathrm{g}}<1\right)$ together with the corresponding linear regression for each protein. The linearity of those plots confirmed the monodispersity of the samples. The maximum dimension $\left(D_{\max }\right)$ values, the radii of gyration $(\mathrm{Rg})$ obtained by Guinier approximation and from the $\mathrm{p}(\mathrm{r})$ functions, as well as the calculated and estimated $\mathrm{M}$ plus the oligomerization states of all the proteins are presented in Table 2 . The Rg values obtained by the two approaches are in close agreement. The most reliable $\mathrm{Rg}$ value for each molecule is that obtained from the $p(r)$ function, derived from the complete experimental curve. As described in Material and Methods, a bovine serum albumin (BSA) solution was used as reference sample for the M estimation using the SAXS data. The results indicated that all the proteins exist in a dimeric state in solution, since the values obtained are approximately twice the values calculated from the primary sequence (Table 2).

\section{$A b$ initio and rigid body model calculations based on SAXS data}

Two ab-initio computational routines were used to calculate the low resolution models for the molecular envelopes of the proteins Sis1, Sis1_ $\Delta_{124-174}$, Sis1_ $\Delta_{121-}$ 257, and Ydj1_ $\Delta_{106-255}$ proteins. The Dummy Atoms (DA) and Dummy Residues (DR) models were derived from the X-ray scattering data introducing a 2-point symmetry constraint in the calculations. This assumption was based on the solution scattering data, which indicated that all the molecules under study were dimers in solution. The crystallographic structure that identified

Table 1 Summary of the hydrodynamic data obtained from DLS and AUC experiments.

\begin{tabular}{|c|c|c|c|c|}
\hline \multirow[t]{2}{*}{ Hydrodynamic properties } & \multicolumn{4}{|c|}{ Protein } \\
\hline & Sis1 & Sis1_ $\Delta_{124-174}$ & Sis1_ $\Delta_{121-257}$ & Ydj1_ $\Delta_{106-255}$ \\
\hline Predicted $M(\mathrm{kDa})^{*}$ & 75.2 & 66.1 & 46.8 & 56.1 \\
\hline Experimental $M(\mathrm{kDa})$ & $64 \pm 3^{\epsilon}$ & $58 \pm 2^{\#} 58 \pm 1^{\epsilon}$ & $45 \pm 2^{\#} 43 \pm 1^{€}$ & $54 \pm 1^{\#} 55 \pm 2^{\epsilon}$ \\
\hline$s^{0}{ }_{20, w}(S)^{\#}$ & $3.5 \pm 0.1 \%$ & $3.4 \pm 0.1$ & $3.0 \pm 0.1$ & $3.6 \pm 0.1$ \\
\hline$S_{\text {sph }}(\mathrm{S})$ & 6.5 & 5.9 & 4.7 & 5.2 \\
\hline$D_{20, w}\left(10^{-7} \mathrm{~cm}^{2} / \mathrm{seg}\right)$ & $5.1 \pm 0.2$ & $5.4 \pm 0.1$ & $6.3 \pm 0.1$ & $5.9 \pm 0.2$ \\
\hline$D_{\text {sph }}\left(10^{-7} \mathrm{~cm}^{2} / \mathrm{seg}\right)$ & 7.7 & 8.0 & 9.0 & 8.45 \\
\hline$f / f_{0} \#$ & $1.6 \pm 0.1$ & $1.6 \pm 0.1$ & $1.5 \pm 0.1$ & $1.4 \pm 0.1$ \\
\hline
\end{tabular}

\footnotetext{
* $M$ predicted from amino acids sequence for all proteins as dimers.

\# data from SV experiments fitted by SedFit software (see Material and methods for details);

${ }^{\epsilon} M$ calculated from $s / D$ ratio as showed by Equation 4;

$\%$ data from [19].
} 


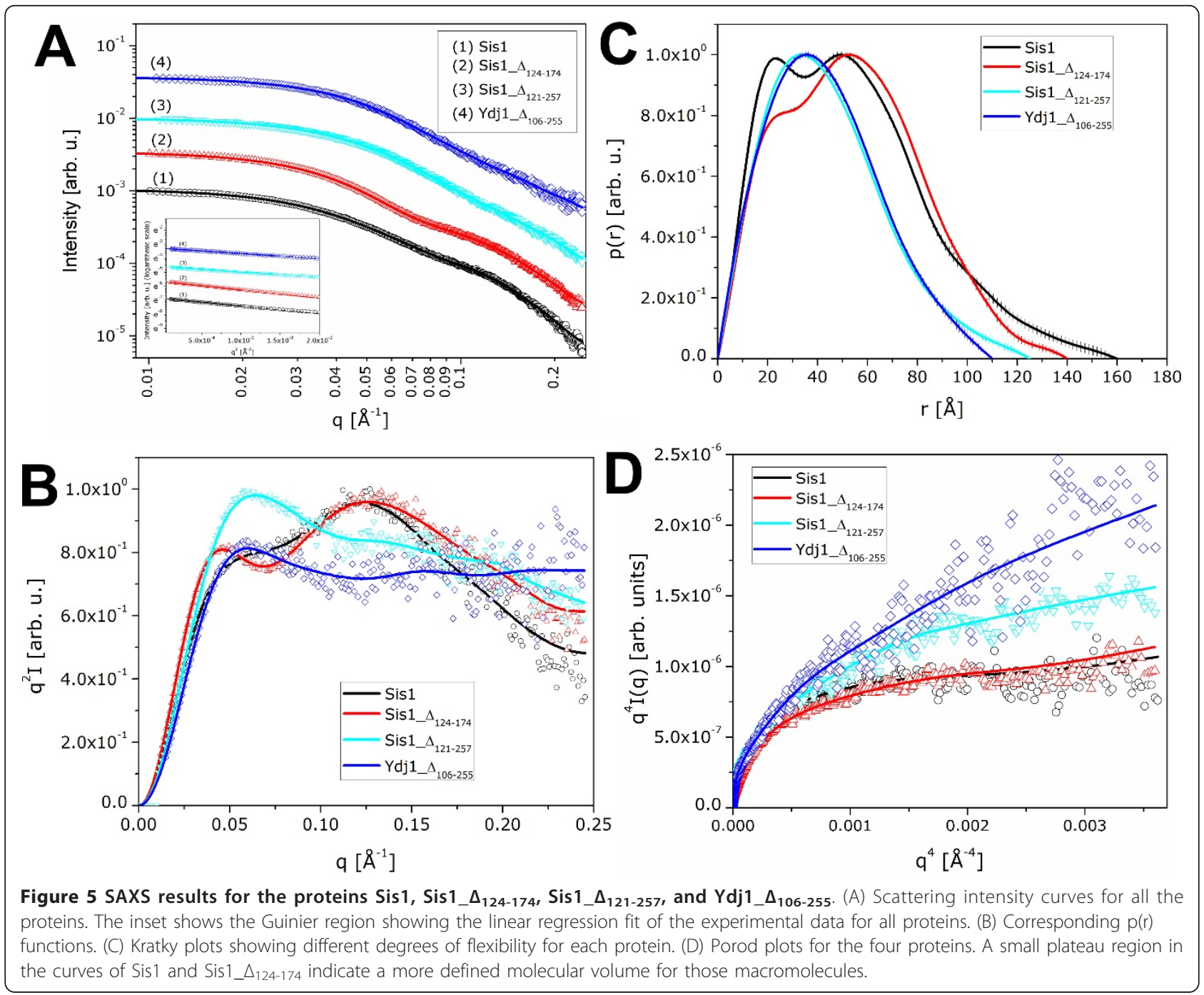

the Sis1 peptide binding fragment as a homodimer in the crystal [20] as well as information on the modeled dimer structure of the Ydj1 peptide binding fragment [25] were taken into account in our calculations. The qrange used in the DAMMIN model calculation was the one generally chosen for the application of this program $\left(\mathrm{q}_{\max } \sim 8 / \mathrm{R}_{\mathrm{g}}\right)$. The full $\mathrm{q}$-range range $\left(0.01<\mathrm{q}<0.25 \AA^{-1} 1\right)$ was used for the DR and rigid body modeling routines (see Methods). Keeping in mind that SAXS $a b$ initio modeling routines do not produce a unique solution,

Table 2 Overall parameters derived from the SAXS results for the proteins Sis1, Sis1_ $\Delta_{124-174}$, Sis1_ $\Delta_{121-257}$ and Ydj1_ $\Delta_{106-255}$

\begin{tabular}{|c|c|c|c|c|}
\hline \multirow[b]{2}{*}{ Structural properties } & \multicolumn{4}{|c|}{ Protein } \\
\hline & Sis 1 & Sis1_ $\Delta_{124-174}$ & Sis1_ $\Delta_{121-257}$ & Ydj1_ $\Delta_{106-255}$ \\
\hline$C(\mathrm{mg} / \mathrm{mL})$ & $7.1,3.1$ & $6.8,4.2$ & $5.2,3.9$ & $5.5,2.75$ \\
\hline $\operatorname{Rg}(\AA ̊)$ (Guinier) & $42 \pm 1$ & $42 \pm 1$ & $35 \pm 1$ & $33 \pm 1$ \\
\hline $\operatorname{Rg}(\AA)($ from $p(r))$ & $43.3 \pm 0.5$ & $42.6 \pm 0.3$ & $35.2 \pm 0.3$ & $34.2 \pm 0.3$ \\
\hline $\operatorname{Dmax}(\AA))$ & 160 & 140 & 125 & 110 \\
\hline M (kDa) (SAXS) & $\sim 71$ & $\sim 69$ & $\sim 42$ & $\sim 47$ \\
\hline Predicted $M(\mathrm{kDa})^{*}$ & 75.2 & 66.1 & 46.8 & 56.1 \\
\hline Oligomerization state & Dimer & Dimer & Dimer & Dimer \\
\hline
\end{tabular}

\footnotetext{
* $M$ predicted from amino acids sequence for all proteins as dimers.
} 
ten independent runs were performed for each calculation.

The resolution of the DA and DR models does not permit an unambiguous determination of the spatial positions of secondary structure elements, but they portray the overall recurring extended shape of the most frequent conformations adopted by these molecules in solution. A spherical start volume was used for the DA modeling calculation in order to minimize the generation of any specific direction for the $\mathrm{p} 2$ symmetry introduced based on the fact that all molecules were dimers. Also, since we were dealing with flexible molecules, it was important to check if the DR and Rigid Body approaches (non initial-volume dependent) were giving similar results. Consequently, rigid body (RB) calculations were performed in an attempt to obtain information on the position of the J-domain and other domains with available crystallographic data to restore the protein structures based on SAXS data. In all cases, we tried to model the molecular envelope of the protein, performing calculations with 2-point symmetry constraints because of the proteins dimeric structure as explained above. Also, as previously mentioned, the dimerization sites of all proteins were known a priori from their X-ray crystallographic structure and this information was used to impose dimerization contact conditions in the RB calculations. The position of the linker between the C-terminal domains and the J-domain of each protein was known from the amino acid sequences. Ten runs were performed for each set of calculations. The multiple runs gave almost coincident results and allowed the identification of the position of the individual domains in the RB models.

The $a b$ initio and rigid body models calculated for the full length Sis1 protein and its deleted-domain mutants are presented in Figure 6. The DA (filter averaged), DR and RB models for proteins Sis1, Sis1_ $\Delta_{124-}$ 174, Sis $1_{-} \Delta_{121-257}$, are shown in panels A, B and C respectively. In the case of the DR models, averaging does not add substantially to the results. So, the models displayed are those presenting the lowest normalized spatial discrepancy (NSD) values, which also showed the best agreement with the DA model. NSDs tend to zero for nearly similar objects and when they exceed 1 , the objects systematically differ from one another (as explained in the Methods section). The NSDs calculated can be considered reasonably good for the DA and DR modeling approaches on account of the flexibility and conformational changes of these molecules. The itemized NSD values for each DA, DR and RB models of Sis1, Sis1_ $\Delta_{124-174}$, Sis1_ $\Delta_{121-257}$, are listed in Table 3.

The filtered average of the ab initio DA model, the DR model with the lowest NSD value and the rigid body model of the Ydj1_ $\Delta_{106-255}$ protein are presented in Figure 7. These results were obtained following the same procedures previously described for the Sis1 full length protein and its deleted domain mutants. The NSD values corresponding to these model calculations (Table 3) also were within the values being considered reasonably good for each different approach. The DR model with the lowest NSD value presents a remarkably good resemblance with the DA and rigid body models,

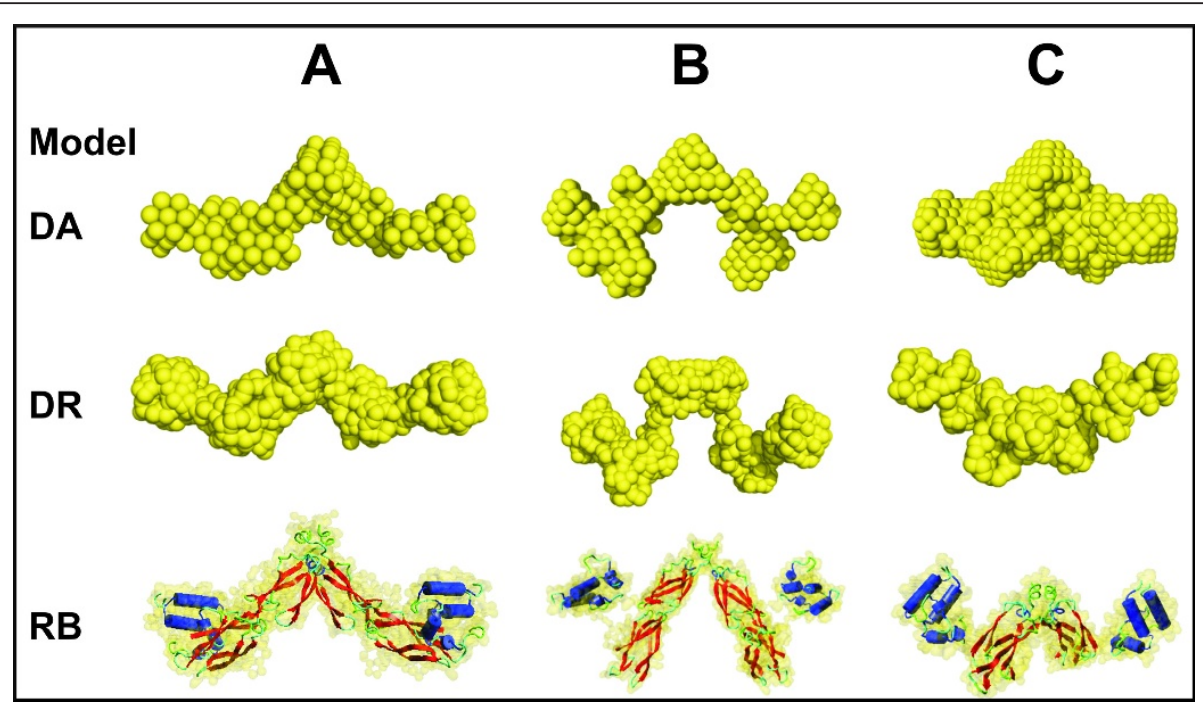

Figure 6 Results of the $a b$ initio (DA and DR) model calculations as well as the rigid body models are displayed for the full length Sis1 protein and its deleted mutants. (A) Sis1, (B) Sis1_ $\Delta_{124-174,}$ (C) Sis1_ $\Delta_{121-257}$ 
Table 3 Normalized Spatial Discrepancy (NSD) range obtained by pairwise comparison of the SAXS models in each group of calculations

\begin{tabular}{|c|c|c|c|c|}
\hline \multirow[b]{2}{*}{ Modelling method } & \multicolumn{4}{|c|}{ Protein } \\
\hline & Sis1 & Sis1_ $\Delta_{124-174}$ & Sis1_ $\Delta_{121-257}$ & Ydj1__ $\Delta_{106-255}$ \\
\hline Dummy atoms & $1.00-1.22$ & $1.17-1.41$ & $0.75-1.01$ & $0.88-1.21$ \\
\hline Dummy residues & $1.41-1.97$ & $1.84-2.68$ & $1.47-1.76$ & $1.38-1.56$ \\
\hline Ab initio and rigid body & $1.95-2.87$ & $1.95-2.51$ & $1.54-1.85$ & $1.87-2.11$ \\
\hline
\end{tabular}

and can be considered an excellent description of the Ydj1_ $\Delta_{106-255}$ protein conformation in solution.

\section{Conclusions}

In previous studies, Ydj1 and Sis1 were found to be homodimers, whose structures differed in the context of the orientation of the J-domain in relation to the longaxis of the respective proteins $[18,19]$. These differences in structure correlate with functional differences exhibited by Ydj1 and Sis1, and the G/F and G/M regions in these proteins were proposed to impact J-domain orientation [15]. To test this hypothesis we carried out hydrodynamic and low-resolution structural studies on Sis1 and Ydj1 deletion mutants. The deletion of the G/F region from Sis1 and Ydj1 had little impact on the function of the J-domain in regulating Hsp70 ATPase

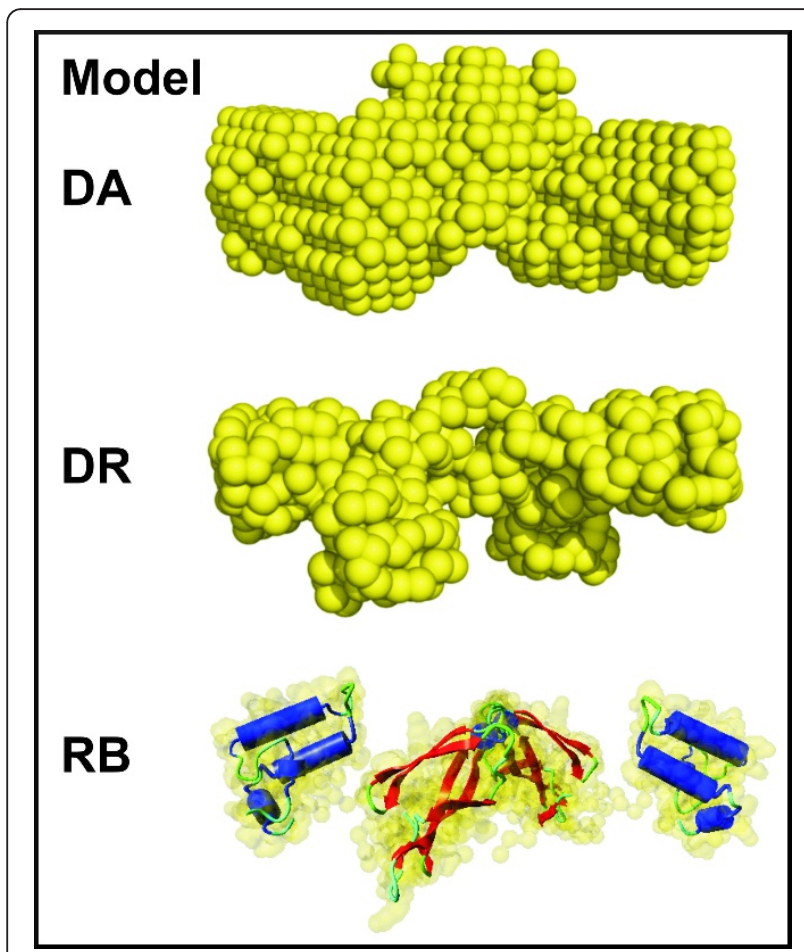

Figure 7 Results of the $a b$ initio (DA and DR) model calculations and the rigid body model obtained for the Ydj1_ $\Delta_{106-255}$ protein, using high resolution data available for some of its domains. activity, but did decrease polypeptide binding activity. Surprisingly, deletion of the G/F region did not change the quaternary structure or overall flexibility of Hsp40s. However, deleting the ZFLR plus the CTDI domain in Type I Ydj1 altered the conformation of J-domains from lying along the long axis of the molecule to be orientated in a crosswise direction as in Type II Sis1. Thus, orientation of J-domains in Type I Hsp40 may be controlled by the ZFLR-CTDI, which is consistent with results from domain swap experiments [15,19]. When these domains are missing, as in the deleted mutants studied here or in the Type II Hsp40s, the J-domains become oriented in a crosswise direction. Our results also point to interactions between the ZFLR-CTDI and the J-domains as an important factor in determining the unique quaternary structure of Type I Hsp40s.

One interesting feature of Type I and Type II Hsp40s that is clear from our data is that these sub-types of Hsp40s are highly flexible. The SAXS intensity data obtained within a wider range of reciprocal space in the present experiments allowed a comparative analysis of the flexible nature of the proteins by means of the Kratky and Porod plots. These results showed that the Type I Ydj1 and Type II Sis1 Hsp40 proteins are highly flexible in solution and confirm the dimerization at the C-terminal. Besides, flexibility was observed in all constructs studied, even after deleting a flexible region (G/ $\mathrm{M})$. So, other flexible regions should exist in the protein in addition to G/M. Prior to the studies presented herein it was assumed that the G/F and G/M domains were the only flexible regions of Hsp40s that enabled the J-domain multiple paths to gain access to the Hsp70 ATPase domain. However, Kratky and Porod analysis of SAXS data on Sis1 and Ydj1 deletion mutants show that both remain highly flexible in the absence of the G/F region. Hsp40s bind and deliver proteins that range from nascent monomeric polypeptides to amyloid-like aggregates to Hsp70. Thus, the overall flexibility of Type I and Type II Hsp40s detected may be important to permit delivery of proteins or different sizes or assembly states to the Hsp70 polypeptide binding site and allow for simultaneous interaction of the J-domains with Hsp70s ATPase domain [5]. These results are also in agreement with crystallographic structural studies reported by $\mathrm{Hu}$ et al. [27], in which they observed that 
the CTDI of human Hsp40 may possess significant flexibility. In their work, the authors proposed an "anchoring and docking" model for Hsp40 in which the flexibility of the CTDI may be important for Hsp40 to regulate the size of the cleft in its interaction with nonnative polypeptides and transfer them to Hsp70.

Functions for the G/F and G/M regions found in Type II Hsp40 in regulation of Hsp70 ATPase activity and/or substrate binding are not clear. Yet, this is an important question because a Sis1 fragment containing just the Jdomain and G/F region is capable of rescuing the lethality of the sis $1 \Delta$ strain [22]. In addition, amino acid residues in the $G / M$ region appear to play a role in specification of Sis1 function [28]. Studies with forms of Sis1 in which the G/M domain was deleted show that loss of the G/M impairs the ability of Sis1 to bind denatured luciferase, but have no effect on regulation of Hsp70 ATPase activity. The G/M region lies adjacent to the hydrophobic grove in CTDI implicated as a polypeptide binding site and methionine has a hydrophobic side chain, which may help to build the proper binding site. Thus, the G/M region helps specify Type II Hsp40 function by assisting in substrate binding.

Since the effects on function are likely to be related to changes in the structure of the Hsp40s, one important objective of this work was to obtain low resolution models of the mutants under study using the latest computational methods available for the spatial representation of these molecules in solution using small angle scattering data. To date, there are crystallographic structures of isolated domains and the quaternary structure of Hsp40s is mainly known as a result of SAXS data from these proteins in solution, combined with other hydrodynamic techniques. Previous structural studies have also proved that Type I Ydj1 and Type II Sis1 have distinct functions and quaternary structures [15,19]. In this work, estimation of molecular masses from SAXS and AUC data indicated that the deletion mutants in solution dimerized at the $\mathrm{C}$-terminal, just like the full-length protein. Thus, it is clear that the $\mathrm{C}$-terminal region is very important for dimerization of both Type I and Type II Hsp40s.

Using three different low-resolution modeling methods, we obtained molecular envelopes for each protein. The rigid body modeling method seemed to be the most appropriate for flexible proteins like Hsp40 and also elucidated the domain arrangement which is important to understand possible functions of the deleted domain mutants in the cell. Interestingly, even deleting some flexible domains of Sis1 and Ydj1, the constructs kept their flexibility and maintained the clamp-like architecture of the full-length protein with the J-domains pointing outwards in opposite directions. This architecture seems to be favorable to the interactions of Hsp40 with Hsp70. The models we built for the proteins seem to agree with the anchoring and docking model, proposed by Qian et al. [10], describing how Hsp40 facilitates the delivery of non-native polypeptides to Hsp70.

\section{Methods}

\section{Protein expression and purification}

The recombinant protein Sis1 and Ydj1 were expressed and purified by two chromatographic steps as previously described $[15,19,21]$. Two Sis1 mutants were prepared from DNA constructions and expressed in Escherichia coli BL21(DE3)pLys: Sis1_ $\Delta_{124-174}$ (pET11aSIS1_ $\Delta_{124-}$ ${ }_{174}$ ), deleting from residues 124 to 174 , and Sis1_ $\Delta_{121-}$ 257 (pET11aSIS1_ $\Delta_{121-257}$ ), deleting from residues 121 to 257. Additionally, one DNA construction for Ydj1 mutant (pET11aYdj1_ $\Delta_{106-255}$ ) deleted from residues 106 to 255, was prepared and was also expressed in $E$. coli BL21(DE3) strain. Cells were grown at $37^{\circ} \mathrm{C}$ up to an optical density at $600 \mathrm{~nm}$ of 0.7 . The temperature was reduced to $30^{\circ} \mathrm{C}$ and the protein expression was induced with $0.4 \mathrm{mM}$ isopropyl thio- $\beta$-D-galactoside (IPTG) during 4 hours. Thereupon, the cells were harvested by centrifugation during $10 \mathrm{~min}$ at $2,600 \times \mathrm{g}$. The pellet was ressuspended in $50 \mathrm{mM}$ Tris- $\mathrm{HCl}(\mathrm{pH}$ 8.0), $500 \mathrm{mM} \mathrm{KCl}$ and $1 \mathrm{mM}$ EDTA $(15 \mathrm{~mL} / \mathrm{L}$ of LB medium). The cells were lysed by adding $30 \mu \mathrm{g} / \mathrm{mL}$ of lysozyme (Sigma) and 5 U of DNAse (GIBCO BRL), kept for $30 \mathrm{~min}$ at ice bath, and then disrupted by sonication and centrifuged ( $30 \mathrm{~min}$ at $26,000 \times \mathrm{g}$ ).

The purification of the proteins was performed as previously described [16,29]. Summarily, Sis1, Sis1_ $\Delta_{124-174}$ and Sis1_ $\Delta_{121-257}$ were submitted to a cationic chromatography in a Macro-prep ${ }^{(\mathrm{TM})}$ High S Support resin (BioRad) using an ÄKTA FPLC device (Pharmacia Biotech). The resin was equilibrated with $20 \mathrm{mM}$ Tris- $\mathrm{HCl}$ buffer ( $\mathrm{pH} 7.5)$ and $20 \mathrm{mM} \mathrm{NaCl}$. Ydj1 and Ydj1_ $\Delta_{106-}$ 255 were submitted to an anionic chromatography in a Macro-prep ${ }^{(\mathrm{R})}$ High Q Support resin (BioRad) using an ÄKTA FPLC device (Pharmacia Biotech). The proteins were eluted by $\mathrm{NaCl}$ gradient, dialyzed overnight against buffer $20 \mathrm{mM}$ Phosphate ( $\mathrm{pH} 7.5$ ), and further purified by chromatography in a $\mathrm{CHT}^{\mathrm{TM}}$ Ceramic Hydroxyapatite Type II resin (BioRad) at an ÄKTA FPLC (Pharmacia Biotech). The target proteins were eluted by a phosphate gradient. Ydj1_ $\Delta_{106-255}$ was further purified by a size exclusion chromatography in a Superdex 200pg using an ÄKTA FPLC (Pharmacia Biotech) previously equilibrated with $25 \mathrm{mM}$ Tris- $\mathrm{HCl}$ buffer $(\mathrm{pH}$ 7.5 ) and $500 \mathrm{mM} \mathrm{NaCl}$. The efficacy of the purification was checked by $12 \%$ SDS-PAGE. Unless stated otherwise, all proteins were diluted in buffer $25 \mathrm{mM}$ Tris$\mathrm{HCl}(\mathrm{pH} 7.5)$ containing $500 \mathrm{mM} \mathrm{NaCl}$. 


\section{Circular dichroism}

Circular dichroism (CD) measurements were performed using a Jasco J-810 spectropolarimeter coupled to a Peltier-type System PFD 425S for temperature control and optimized for best performance as previously described [30]. The proteins were re-suspended in buffer $25 \mathrm{mM}$ Tris- $\mathrm{HCl}$ (pH 7.5) containing $500 \mathrm{mM} \mathrm{NaCl}$. Proteins concentration ranged from 10 to $40 \mu \mathrm{M}$ and the spectra were collected at a scan rate of $50 \mathrm{~nm} / \mathrm{min}$ with a spectral bandwidth of $1 \mathrm{~nm}$ and using a $0.2 \mathrm{~mm}$ path length cell.

\section{Chaperone activity}

Hsp40s activities were tested by their ability to bind heated denaturated luciferase and to stimulate Hsp70 Ssa1 ATPase activity as previously described [15,21]. The ability to bind heated luciferase (a client protein) was tested and the Sis 1 binding was set as standard (100\%). With respect to Hsp40s ability to stimulate the ATPase activity of Hsp70, the mutants were assayed regarding their ability to stimulate ATP hydrolysis of Ssa1 (Hsp70) and the Sis1 stimulatory effect was set as standard (100\%).

\section{Dynamic Light Scattering}

The experimental diffusion coefficient (D) was obtained by dynamic light scattering (DLS) using a DynaPro-MS/ $\mathrm{X}$ device (Protein Solutions). The experiments were performed at $20^{\circ} \mathrm{C}$, and proteins concentration ranged from 0.5 to $2.0 \mathrm{mg} / \mathrm{mL}$. The $\mathrm{D}$ value was corrected to standard conditions $\left(D_{20, w}\right)$ and extrapolated to $0 \mathrm{mg} / \mathrm{mL}$ concentration $\left(\mathrm{D}^{0}{ }_{20, \mathrm{w}}\right)$ in order to avoid effects of viscosity and temperature. $\mathrm{D}$ is related to the frictional coefficient $(f)$ by the following equation:

$$
D=\frac{R T}{N_{A} f}
$$

where $\mathrm{T}$ is the absolute temperature, $\mathrm{R}$ is the gas constant and $\mathrm{N}_{\mathrm{A}}$ is the Avogadro's number.

For a protein with known Stokes radius (Rs) and viscosity $(\eta), f$ can be obtained applying the Stokes equation:

$$
f=6 \pi \eta R s
$$

For comparison, the frictional coefficient for a spherical particle $\left(f_{0}\right)$ can be calculated using the predicted Stokes radius $\left(\mathrm{R}_{0}\right)$ for a smooth and compact spherical protein of molecular mass $\mathrm{M}$ :

$$
R_{0}=\left(\frac{3 M V_{b a r}}{4 \pi N_{A}}\right)^{1 / 3}
$$

where $V_{\text {bar }}$ is the partial specific volume, $f_{0}$ is used to obtain the maximum diffusion coefficient $\left(D_{\text {sph }}\right)$ applying equation 1 and the frictional ratio $\left(f / f_{0}\right)$ is used to indicate particle asymmetry when compared to a globular protein of same $\mathrm{M}$ giving information on the shape of the proteins $[26,31]$.

\section{Analytical Ultracentrifugation}

Analytical ultracentrifugation (AUC) experiments were performed in a Beckman Optima XL-A analytical ultracentrifuge. Sedimentation velocity (SV) experiments were carried out in concentrations ranging from 150 to $1,000 \mu \mathrm{g} / \mathrm{mL}$. The SV experiments were performed at $20^{\circ} \mathrm{C}$, using 30,000 rpm (AN-60Ti rotor) for Sis $1_{-} \Delta_{121}$ 257 and Ydj1_ $\Delta_{106-255}$, and 25,000 rpm for Sis1_ $\Delta_{124-174}$. The SedFit software (Version 9.4) was used to deconvolute the sedimentation and diffusion data in order to obtain the continuous sedimentation distribution $\mathrm{c}(\mathrm{S})$ and a weight average value of frictional ratio. The $f / f_{0}$ value was used as a parameter of the regularization function and also used to estimate the molecular mass from the $\mathrm{c}(\mathrm{M})$ plots $[32,33]$. The apparent sedimentation coefficients (s) were obtained from the maximum peak values of the $c(S)$ curves. The standard sedimentation coefficients $\left(\mathrm{s}_{20, \mathrm{w}}\right)$ at each protein concentration were estimated to avoid interferences caused by viscosity and density increment [26,31]. The Sednterp software http:// www.jphilo.mailway.com/download.htm was used to estimate important hydrodynamic parameters: (1) the partial specific volume $\left(\mathrm{V}_{\mathrm{bar}}\right)$ for Sis1 $(0.7263 \mathrm{~mL} / \mathrm{g})$, Sis1_ $\Delta_{124-174}(0.7312 \mathrm{~mL} / \mathrm{g}), \operatorname{Sis} 1 \_\Delta_{121-257}(0.7284 \mathrm{~mL} / \mathrm{g})$ and Ydj1_ $\Delta_{106-255}(0.7331 \mathrm{~mL} / \mathrm{g})$ from their amino acid sequence; (2) the $\mathrm{s}_{\mathrm{sph}}$ and $\mathrm{D}_{\mathrm{sph}}$ for a globular protein of same molecular mass $M$ and buffer viscosity $(\eta=1.0605$ $\mathrm{x} 10^{-2}$ poise) and density ( $\left.\rho=1.01938 \mathrm{~g} / \mathrm{mL}\right)$; and (3) to correct the apparent value of $s$ to $s_{20, w}$. The standard sedimentation coefficient extrapolated to $0 \mathrm{mg} / \mathrm{mL}\left(\mathrm{s}^{0}{ }_{20}\right.$, w) was calculated by linear regression from values of $s_{20}$, ${ }_{w}$ versus the protein concentration. The molecular mass values were obtained as the ratio of the sedimentation to diffusion coefficient using the following equation.

$$
M=\frac{s R T}{D\left(1-V_{b a r} \rho\right)}
$$

\section{Small-Angle X-ray scattering experiments}

SAXS experiments were performed at the D02A-SAXS2 beamline of the Laboratório Nacional de Luz Síncrotron (LNLS, Campinas-SP, Brazil). The X-ray scattering data were recorded using a two-dimensional position-sensitive MARCCD detector. The measurements were performed with a monochromatic X-ray beam (wavelength of $\lambda=1.488 \AA$ ) and a sample-to-detector distance of $1374.4 \mathrm{~mm}$, corresponding to the scattering vector range of $0.01<\mathrm{q}<0.25 \AA^{-1}$, where $\mathrm{q}$ is the magnitude 
of the q-vector defined by ( $2 \theta$ is the scattering angle). The samples were placed in a $1-\mathrm{mm}$ path length cell with mica windows [34]. The scattering patterns were recorded at two different sample concentrations for each sample: 7.1 and $3.1 \mathrm{mg} / \mathrm{mL}$ for Sis1, 6.8 and 4.2 $\mathrm{mg} / \mathrm{mL}$ for Sis1_ $\Delta_{124-174}, 5.2$ and $3.9 \mathrm{mg} / \mathrm{mL}$ for Sis1_ $\Delta_{121-257}$, and 5.5 and $2.75 \mathrm{mg} / \mathrm{mL}$ for Ydj1_ $\Delta_{106-255}$. All the samples were measured in buffer $25 \mathrm{mM}$ Tris$\mathrm{HCl}(\mathrm{pH} 7.5)$ containing $500 \mathrm{mM} \mathrm{NaCl}$. Three successive frames of 300 s each were recorded for each sample and two frames more for the buffer. The scattering curves were individually corrected for detector response and scaled by the incident beam intensity and the samples absorption. The corrected buffer scattering curve was subtracted from the corresponding sample scattering. The resulting curves were normalized by the respective concentrations and carefully inspected to check for possible radiation-induced damage and concentration effects, but such effects were not observed. A $5.6 \mathrm{mg} /$ $\mathrm{mL}$ bovine serum albumin (BSA, $66 \mathrm{kDa}$ ) solution was used as a standard sample to determine the molecular mass of the proteins. The molecular mass was estimated by comparison of the extrapolated value of the intensity at the origin value, $\mathrm{I}(0)$, of the samples scattering data with that from the reference solution of Bovine Serum Albumin (BSA) as described in Orthaber et al. [35] and Mylonas et al. [36].

\section{SAXS data analysis}

Determination of the radius of gyration $\left(\mathrm{R}_{\mathrm{g}}\right)$ was performed using the Guinier approximation:

$$
I(q)=I(0) \exp \left(-q^{2} R_{g}^{2} / 3\right)
$$

valid in the q-range where $\mathrm{qR}_{\mathrm{g}}<1$ [37-39]. The linearity of the scattering curves in the validity region confirmed monodispersity of the samples and allowed further analysis. Moreover, $\mathrm{R}_{\mathrm{g}}$ values were also evaluated from the pair distance distribution function $\mathrm{p}(\mathrm{r})$ calculated from the scattering intensity data by means of the Indirect Fourier Transform package GNOM [40]. The p (r) function also provided the maximum dimension $\mathrm{D}_{\max }$ of the molecule, because $\mathrm{p}\left(\mathrm{r} \geq \mathrm{D}_{\max }\right)=0[38,39]$. Both the Guinier approximation, and the calculated $\mathrm{p}(\mathrm{r})$ function provided values for the forward scattering intensity $\mathrm{I}(0)$. These $\mathrm{I}(0)$ values were used for the estimation of the molecular mass. The confirmation of the monodispersity and dimerization of the Sis1, Sis1_ $\Delta_{124-}$ 174, Sis1_ $\Delta_{121-257}$, and Ydj1_ $\Delta_{106-255}$ proteins was inferred from the molecular mass obtained for these proteins. The flexibility of the molecules was estimated from the scattered intensity analyzing the behavior of the Kratky curves $\left(\mathrm{q}^{2} \mathrm{I}(\mathrm{q})\right.$ versus $\left.\mathrm{q}\right)[38,39]$ and Porod plots $\left(q^{4} I(q)\right.$ versus $\left.q^{4}\right)$. These representations provided qualitative information about the degree of flexibility and compactness [38,39,41-43].

\section{Ab initio modeling based on SAXS data}

$\mathrm{Ab}$ initio calculations based on SAXS data were performed to obtain low-resolution models for the conformation of the following proteins: Sis1, Sis1_ $\Delta_{124-174}$, Sis1_ $\Delta_{121-257}$, and Ydj1_ $\Delta_{106-255}$. Two different ab initio approaches were applied using the dummy atoms (DA) and dummy residues (DR) modeling methods. Given the existence of a certain flexibility in these proteins those two types of calculations were necessary to identify the existence of common structural features between the different models. The dummy atoms modeling method provided a bead model whose calculated intensity fitted the experimental SAXS curve (see Figure S1 in Additional file 1). This DA approach was implemented using the program DAMMIN [44] in the q-range $\left(\mathrm{q}_{\max }<8 / \mathrm{R}_{\mathrm{g}}\right)$ which ends up being slightly different for each protein.

Since no unique solution can be obtained from this calculation, several independent calculations were performed. Thereupon, the models were pair wise compared and then averaged using programs of the DAMAVER suite [45] and SUPCOMB [46]. The latter program aligns two models represented by ensembles of points by minimizing a dissimilarity measure called Normalized Spatial Discrepancy (NSD). Generally, NSD values tend to zero for increasingly similar objects; when they significantly exceed 1 , the objects systematically differ from one another [46]. Subsequently, new calculations were performed for each protein using the DR approach. The dummy residues modeling method provides further insights into the possible three dimensional conformation of the proteins and their deleted mutants in solution. This was implemented using the program GASBOR [47] using the full range of q values. Again, several independent calculations were performed and the NSD values were evaluated. However, an average of the DR representations does not substantially improve the quality of the models due to the flexibility of the molecules. So, a quantitative analysis of the NSD values obtained from the several models was also performed in order to obtain the most appropriate molecular conformation (i.e., the model having the lowest average NSD value), to describe the low resolution structure of the protein.

\section{SAXS-based Modeling of the multidomain arrangement for all proteins studied}

The topology of each protein and each deleted-domain mutant of Sis1 was examined by applying a rigid body modeling method to the SAXS data. This approach employs a simulated annealing protocol to find the optimal positions and orientations of high-resolution structures of the known regions of the protein. At the same 
time, the conformation obtained for the unknown regions (flexible linker attached to the appropriate residues of the domains) was calculated finding the best fit to the experimental scattering data. The rigid body calculations were implemented by the program $\mathrm{BUNCH}$ [48] using the full q-range. In order to construct the model of the mutants of Sis1, we used the high resolution structure of the Sis1 C-terminal peptide-binding domain and the Sis1 J-domain, both found in the Protein Data Bank http://www.rcsb.org identified by the codes $1 \mathrm{C} 3 \mathrm{G}$ and $2 \mathrm{O} 37$ respectively. To compose the model for the Ydj1 deleted domain mutant, we used the high resolution structure of the Ydj1 dimerization domain (PDB code 1XAO) and also the J-domain from the Sis1 structure (PDB code 2O37). Several independent calculations were performed for each protein. We applied a 2-point symmetry constraint to the model calculations, using the a priori knowledge that all of them were dimers in solution. The NSD values were evaluated in order to select the most typical model for each protein. The fits for the models (Figure S1) and the corresponding chi values (Table S1) can be found in additional files 1 and 2 respectively.

\section{Additional material}

Additional file 1: Figure S1. Model fits for the four proteins studied in this work.

Additional file 2: Table S2. Chi-values (root mean square of $\chi^{2}$ ) obtained from the fit of the theoretical scattering calculated from the models of the experimental intensity curve.

\section{Acknowledgements and Funding}

This research was supported by the Brazilian Synchrotron Light Laboratory (LNLS)/Ministry of Science and Technology (MCT) and the State of São Paulo Research Foundation (FAPESP). Research in the laboratory of $\mathrm{CHIR}$ is supported by grants from FAPESP, and MCT/National Research Council (MCT/CNPq), and NIH-R03TW007437 funded by the Fogarty International Center (FIRCA-NIH). J.C. Silva thanks FAPESP and CNPq for financial support and FIRCA-NIH for paying for travelling expenses for training. J.C. Borges thanks FIRCA-NIH for fellowship, FAPESP (2007/05001-4) for financial support and CNPq for Research Fellowship. ILT is a CNPq (1B) Research Fellow, and CHIR a CNPq (1C) Research Fellow. DMC is supported by NIH RO1GM067785.

\section{Author details}

'Department of Condensed Matter Physics, "Gleb Wataghin" Physics Institute, State University of Campinas (UNICAMP), Campinas, SP 13083-859, Brazil. ${ }^{2}$ Brazilian Biosciences National Laboratory, Center for Research in Energy and Materials (CNPEM), Campinas, SP 13083-970, Brazil. ${ }^{3}$ Institute of Chemistry of São Carlos, University of São Paulo, São Carlos, SP 13.560-970, Brazil. ${ }^{4}$ Department of Cell and Developmental Biology, University of North Carolina, Chapel Hill, NC 27599, USA. ${ }^{5}$ Department of Organic Chemistry, Institute of Chemistry, University of Campinas UNICAMP, SP 13083-970, Brazil. ${ }^{6}$ European Synchrotron Radiation Facility, Grenoble, France.

\section{Authors' contributions}

ILT and CHIR conceived and designed the experiments. JCS performed the SAXS experiments, data analysis, modeling calculations and interpreted them together with ILT. JCB produced and purified all proteins, executed the hydrodynamics and spectroscopic experiments and interpreted them together with CHIR. DMC produced the deletion mutants and performed the functional experiments. All authors organized the results, wrote the manuscript, read and approved the final version of the manuscript.

Received: 17 June 2011 Accepted: 19 October 2011

Published: 19 October 2011

\section{References}

1. Fink AL: Chaperone-mediated protein folding. Physiol Rev 1999, 79:425-449.

2. Hartl FU: Molecular chaperones in cellular protein folding. Nature 1996, 381:571-580.

3. Hartl FU, Hayer-Hartl M: Protein folding - Molecular chaperones in the cytosol: from nascent chain to folded protein. Science 2002, 295:1852-1858.

4. Bukau B, Horwich AL: The Hsp70 and Hsp60 chaperone machines. Cell 1998, 92:351-366.

5. Summers DW, Douglas PM, Ramos CHI, Cyr DM: Polypeptide transfer from Hsp40 to Hsp70 molecular chaperones. Trends Biochem Sci 2009, 34:230-233.

6. Langer T, Lu C, Echols H, Flanagan J, Hayer MK, Hartl FU: Successive Action of Dnak, Dnaj and Groel Along the Pathway of Chaperone-Mediated Protein Folding. Nature 1992, 356:683-689.

7. Schmid D, Baici A, Gehring H, Christen P: Kinetics of Molecular Chaperone Action. Science 1994, 263:971-973.

8. Misselwitz B, Staeck O, Rapoport TA: J proteins catalytically activate hsp70 molecules to trap a wide range of peptide sequences. Mol Cell 1998, 2:593-603.

9. Laufen T, Mayer MP, Beisel C, Klostermeier D, Mogk A, Reinstein J, et al: Mechanism of regulation of Hsp70 chaperones by DnaJ cochaperones. Proc Natl Acad Sci USA 1999, 96:5452-5457.

10. Qian XG, Hou WB, Li ZG, Sha BD: Direct interactions between molecular chaperones heat-shock protein ( $\mathrm{Hsp}) 70$ and Hsp40: yeast Hsp70 Ssa1 binds the extreme C-terminal region of yeast Hsp40 Sis1. Biochem J 2002, 361:27-34.

11. Cyr DM, Langer T, Douglas MG: Dnaj-Like Proteins - Molecular Chaperones and Specific Regulators of Hsp70. Trends Biochem Sci 1994, 19:176-181.

12. Wall D, Zylicz M, Georgopoulos C: The Nh2-Terminal 108 Amino-Acids of the Escherichia-Coli Dnaj Protein Stimulate the Atpase Activity of Dnak and Are Sufficient for Lambda-Replication. J Biol Chem 1994, 269:5446-5451.

13. Luke MM, Sutton A, Arndt KT: Characterization of Sis1, A SaccharomycesCerevisiae Homolog of Bacterial Dnaj Proteins. J Cell Biol 1991, 114:623-638

14. Caplan AJ, Douglas MG: Characterization of Ydj1 - A Yeast Homolog of the Bacterial Dnaj Protein. J Cell Biol 1991, 114:609-621.

15. Fan CY, Lee S, Ren HY, Cyr DM: Exchangeable chaperone modules contribute to specification of type I and type II Hsp40 cellular function. Mol Biol Cell 2004, 15:761-773.

16. Lu Z, Cyr DM: Protein folding activity of Hsp70 is modified differentially by the Hsp40 co-chaperones Sis1 and Ydj1. J Biol Chem 1998, 273:27824-27830.

17. Banecki B, Liberek K, Wall D, Wawrzynow A, Georgopoulos C, Bertoli E, et al: Structure-function analysis of the zinc finger region of the DnaJ molecular chaperone. J Biol Chem 1996, 271:14840-14848.

18. Borges JC, Fischer $\mathrm{H}$, Craievich AF, Ramos $\mathrm{CHI}$ : Low resolution structural study of two human HSP40 chaperones in solution - DjA1 from subfamily $A$ and DjB4 from subfamily $B$ have different quaternary structures. J Biol Chem 2005, 280:13671-13681.

19. Ramos CHI, Oliveira CLP, Fan CY, Torriani IL, Cyr DM: Conserved Central Domains Control the Quaternary Structure of Type I and Type II Hsp40 Molecular Chaperones. J Mol Biol 2008, 383:155-166.

20. Sha BD, Lee $S, C y r$ DM: The crystal structure of the peptide-binding fragment from the yeast Hsp40 protein Sis1. Structure 2000, 8:799-807.

21. Lee S, Fan CY, Younger JM, Ren HY, Cyr DM: Identification of essential residues in the Type II Hsp40 Sis1 that function in polypeptide binding J Biol Chem 2002, 277:21675-21682.

22. Yan W, Craig EA: The glycine-phenylalanine-rich region determines the specificity of the yeast Hsp40 Sis1. Mol Cell Biol 1999, 19:7751-7758. 
23. Johnson $\lrcorner$, Craig EA: An essential role for the substrate-binding region of hsp40s in Saccharomyces cerevisiae. J Cell Biol 2001, 152:851-856.

24. Sondheimer N, Lopez N, Craig EA, Lindquist S: The role of Sis1 in the maintenance of the [RNQ(+)] prion. EMBO J 2001, 20:2435-2442.

25. Li JZ, Oian XG, Sha B: The crystal structure of the yeast Hsp40 Ydj1 complexed with its peptide substrate. Structure 2003, 11:1475-1483.

26. Borges JC, Ramos CHI: Analysis of molecular targets of mycobacterium tuberculosis by analytical ultracentrifugation. Curr Med Chem 2011, 18:1276-1285.

27. $\mathrm{Hu} J \mathrm{~B}, \mathrm{Wu}$ YK, Li JZ, Qian XG, Fu ZQ, Sha BD: The crystal structure of the putative peptide-binding fragment from the human $\mathrm{Hsp} 40$ protein $\mathrm{Hdj} 1$. BMC Struct Biol 2008, 8.

28. Lopez N, Aron R, Craig EA: Specificity of class II Hsp40 Sis1 in maintenance of yeast prion [RNQ(+)]. Mol Biol Cell 2003, 14:1172-1181.

29. Lu Z, Cyr DM: The conserved carboxyl terminus and zinc finger-like domain of the co-chaperone Ydj1 assist Hsp70 in protein folding. J Biol Chem 1998, 273:5970-5978.

30. Correa DHD, Ramos CHI: The use of circular dichroism spectroscopy to study protein folding, form and function. African J Biochem Res 2009, 3:164-173.

31. Lebowitz J, Lewis MS, Schuck P: Modern analytical ultracentrifugation in protein science: A tutorial review. Protein Sci 2002, 11:2067-2079.

32. Schuck P, Perugini MA, Gonzales NR, Howlett GJ, Schubert D: Sizedistribution analysis of proteins by analytical ultracentrifugation: Strategies and application to model systems. Biophys J 2002, 82:1096-1111.

33. Schuck P: Size-distribution analysis of macromolecules by sedimentation velocity ultracentrifugation and Lamm equation modeling. Biophys J 2000, 78:1606-1619.

34. Cavalcanti LP, Torriani IL, Plivelic TS, Oliveira CLP, Kellermann G, Neuenschwander R: Two new sealed sample cells for small angle x-ray scattering from macromolecules in solution and complex fluids using synchrotron radiation. Rev Sci Inst 2004, 75:4541-4546.

35. Orthaber D, Bergmann A, Glatter O: SAXS experiments on absolute scale with Kratky systems using water as a secondary standard. J App/ Cryst 2000, 33:218-225.

36. Mylonas E, Svergun DI: Accuracy of molecular mass determination of proteins in solution by small-angle X-ray scattering. J Appl Cryst 2007, 40: S245-S249.

37. Fournet G, Guinier A: Small angle scattering of X-rays. Translated by Walker, C.B. and Yudowitch, K.L. New York: John Wiley \& Sons; 1955, 7-78.

38. Feigin LA, Svergun DI: Structure analysis by small-angle X-ray and neutron scattering. New York: Plenum Press; 1987, 59-104.

39. Glatter O, Kratky O: Small Angle X-Ray Scattering. New York: Academic Press Inc. Ltd; 1982, 17-50.

40. Svergun Dl: Determination of the Regularization Parameter in IndirectTransform Methods Using Perceptual Criteria. J Appl Cryst 1992, 25:495-503.

41. Perez J, Vachette P, Russo D, Desmadril M, Durand D: Heat-induced unfolding of neocarzinostatin, a small all-beta protein investigated by small-angle X-ray scattering. J Mol Biol 2001, 308:721-743.

42. Moncog K, Broutin I, Craescu CT, Vachette P, Ducruix A, Durand D: SAXS study of the PIR domain from the Grb14 molecular adaptor: A natively unfolded protein with a transient structure primer? Biophys J 2004 , 87:4056-4064.

43. Calmettes P, Durand D, Desmadril M, Minard P, Receveur V, Smith JC: How Random Is A Highly Denatured Protein. Biophys Chem 1994, 53:105-113.

44. Svergun DI: Restoring low resolution structure of biological macromolecules from solution scattering using simulated annealing. Biophys J 1999, 76:2879-2886

45. Volkov W, Svergun DI: Uniqueness of ab initio shape determination in small-angle scattering. J Appl Cryst 2003, 36:860-864.

46. Kozin MB, Svergun DI: Automated matching of high- and low-resolution structural models. J Appl Cryst 2001, 34:33-41.

47. Svergun DI, Petoukhov MV, Koch MHJ: Determination of domain structure of proteins from X-ray solution scattering. Biophys J 2001, 80:2946-2953.

48. Petoukhov MV, Svergun DI: Global rigid body modeling of macromolecular complexes against small-angle scattering data. Biophys $J$ 2005, 89:1237-1250. doi:10.1186/1472-6807-11-40

Cite this article as: Silva et al:: Central domain deletions affect the SAXS solution structure and function of Yeast Hsp40 proteins Sis1 and Ydj1. BMC Structural Biology 2011 11:40.

\section{Submit your next manuscript to BioMed Central and take full advantage of:}

- Convenient online submission

- Thorough peer review

- No space constraints or color figure charges

- Immediate publication on acceptance

- Inclusion in PubMed, CAS, Scopus and Google Scholar

- Research which is freely available for redistribution

Submit your manuscript a www.biomedcentral.com/submit
Biomed Central 